\title{
Use of inductively coupled plasma atomic emission spectrometry for determination of iron, aluminium and phosphorus in Tamm's soil extracts
}

\author{
I. Novozamsky, R. van Eck, V. J. G. Houba and J. J. van der Lee \\ Department of Soil Science and Plant Nutrition, Agricultural University, De \\ Dreijen 3, 6703 BC Wageningen, Netherlands
}

Received 14 June 1985; accepted 14 January 1986

Key words: ICP-AES, iron, aluminium, phosphorus, oxalate extraction, soils, soil analysis

\begin{abstract}
Iron, aluminium and phosphorus were determined by ICP atomic emission spectrometry in an ammonium oxalate-oxalic acid extract of soil. Measuring conditions were optimized towards phosphorus. Transport interferences were prevented by diluting and acidifying the sample solutions. Spectral interferences on phosphorus were found with $\mathrm{Fe}, \mathrm{Al}$ and $\mathrm{Cu}$.

A correction may be made for soils high in $\mathrm{Al}$ and/or Fe. The analytical results for all three elements $\mathrm{Fe}, \mathrm{Al}$ and $\mathrm{P}$ showed good agreement with other methods of determination.
\end{abstract}

\section{Introduction}

An acid ammonium oxalate solution, which contains $\left(\mathrm{COONH}_{4}\right)_{2}$ at $0.175 \mathrm{~mol} / \mathrm{l}$ and $(\mathrm{COOH})_{2}$ at $0.100 \mathrm{~mol} / \mathrm{l}$ and has a $\mathrm{pH}$ value of 3.25 , is commonly known as Tamm's reagent (Tamm, 1934). Several modifications have been proposed, for example $0.113 \mathrm{~mol} / 1\left(\mathrm{COONH}_{4}\right)_{2}$ and $0.087 \mathrm{~mol} / 1(\mathrm{COOH})_{2}$ with $\mathrm{pH} 3.0$ (Schwertmann, 1964). These solutions are recognized as selective extraction agents for the active colloidal fraction of iron and aluminium in soils, provided that the extraction is carried out in the dark. This extraction was also found to be very useful for assessing the phosphate retention characteristics of soils (Schlichting, 1962; Saunders, 1965; Beek, 1980). For this purpose, the phosphate concentration in the extract has to be measured as well as the aluminium and iron concentration. The latter two can be determined rapidly by flame atomic absorption spectrometry (FAAS) (Blakemore, 1968), but for the determination of phosphorus - by means of the molybdenum blue method (Murphy \& Riley, 1962) - the extract has to be digested, a procedure which substantially slows down the rate of analysis. This calls for an analytical 
technique with multi-element capability and without pre-digestion. Both requirements are met by the technique of inductively coupled plasma atomic emission spectrometry (ICP-AES).

Moreover, this technique has high sensitivity and relative freedom from chemical interferences. The plasma conditions are suitable for the excitation and measurement of non-metals such as phosphorus too. Notwithstanding these advantages, spectral and matrix interference effects are a potential source of error. This paper reports the (virtually simultaneous) determination of aluminium, iron and phosphorus in oxalate extracts of soils by means of ICP-AES. Actual and potential interelement interferences in the plasma are discussed together with procedures to overcome these interferences.

\section{Materials and methods}

\section{Instrumentation}

The apparatus used in this investigation was a commercially available Perkin-Elmer ICP/5500, equipped with a holographic UV grating of 2880 grooves per $\mathrm{mm}$, blazed at $210 \mathrm{~nm}$, focal length $408 \mathrm{~mm}$, resulting in a spectral band width of $0.03 \mathrm{~nm}$. The ICP unit is crystal-controlled at $27.12 \mathrm{MHz}$; intensity measurements at preselected wavelengths are taken sequentially. The read-out system is interfaced with an 8-bit 64 kByte micro-computer with a dual floppy disc unit, a video screen and a printer. Gross line intensities were measured at $214.91 \mathrm{~nm}$ (P I), $396.15 \mathrm{~nm}$ (Al I) and $238.20 \mathrm{~nm}$ (Fe II). Background intensities were obtained by measuring blank solutions. Operating parameters (Table 1) were optimized for the phosphorus line.

\section{Sample preparation for ICP-AES}

Sandy soils with a low $\mathrm{P}$ content and a high $\mathrm{Cu}$ content were available from another investigation. Twenty of those were chosen at random.

From several slightly different extraction procedures, the one used by Beek (1980) was adopted. In this procedure $2.50 \mathrm{~g}$ of air-dry soil (particle size $<2 \mathrm{~mm}$ ) is extracted by $50 \mathrm{ml}$ of a solution which contains ammonium oxalate at $0.200 \mathrm{~mol} / \mathrm{l}$ and oxalic acid at $0.140 \mathrm{~mol} / \mathrm{l}$. The extraction time was $120 \mathrm{~min}$ at 120 oscillations/min on a linear, mechanical shaker in a darkened room at $20 \pm 1{ }^{\circ} \mathrm{C}$. Thereafter the suspensions were filtered over paper. An aliquot of each filtrate was

Table 1. Operating parameters.

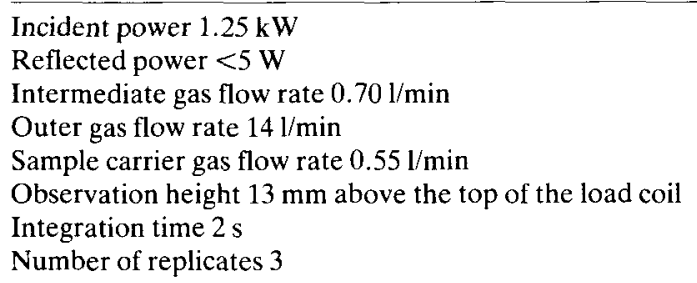


acidified with $\mathrm{HCl}$ and diluted tenfold so as to obtain a final solution containing $\mathrm{HCl}$ at $0.1 \mathrm{~mol} / \mathrm{l}$.

Conventional nebulizers (the pneumatic cross-flow type) can only operate efficiently if aspirated solutions contain less than $0.5 \%$ total dissolved solids. Since the extracts contained some $37.4 \mathrm{~g} \mathrm{l}^{-1}$ of oxalates, dilution was necessary. A dilution factor of 10 had to be applied so as to achieve consistent results. Furthermore, in order to increase the solubility of the oxalates present and to prevent the build-up of solids in the central torch tube, all solutions were acidified with $\mathrm{HCl}$ up to a concentration of $0.1 \mathrm{~mol} / 1$. The reproducibility was increased by addition of glycerol to all solutions to an extent of $1 \%(\mathrm{v} / \mathrm{v})($ van Eck, 1978).

\section{Measurements}

Each solution was analysed for $\mathrm{P}, \mathrm{Al}$ and Fe by ICP-AES. For the calibration, series of mixed standard solutions were prepared which contained up to $10 \mathrm{mg} \mathrm{l}^{-1}$ of $P$, $\mathrm{Al}$ and $\mathrm{Fe}$, and had the same concentrations of oxalate, $\mathrm{HCl}$ and glycerol as the diluted soil extracts. The ICP measurements were done in triplicate, i.e. three readings of the same measuring solution were taken with intervals of 10-15 seconds while the solution was nebulized continuously. For comparison, the concentrations of $\mathrm{Al}$ and $\mathrm{Fe}$ in the filtrates were determined by FAAS, with a $\mathrm{C}_{2} \mathrm{H}_{2} / \mathrm{N}_{2} \mathrm{O}$ flame at $309.3 \mathrm{~nm}$ and $\mathrm{a}_{2} \mathrm{H}_{2} /$ air flame at $248.3 \mathrm{~nm}$, respectively. The phosphate concentration was measured in a separate aliquot by the molybdenum blue method after preceding digestion of the extract by concentrated $\mathrm{H}_{2} \mathrm{SO}_{4}$ and $\mathrm{H}_{2} \mathrm{O}_{2}$. These determinations were carried out independent of ICP determinations, i.e. on a different subsample, by another operator at another time.

\section{Results and discussion}

\section{Spectral interferences}

Solutions containing $10 \mathrm{mg} \mathrm{l}^{-1}$ of $\mathrm{P}, \mathrm{Al}$ and $\mathrm{Fe}$ were aspirated for spectral calibration of the analytical wavelengths and for calibration of the sensitivity ('gain'). Then solutions containing $1000 \mathrm{mg} \mathrm{l}^{-1}$ of $\mathrm{Al}, \mathrm{Ca}, \mathrm{Cu}, \mathrm{Fe}, \mathrm{K}, \mathrm{Mg}, \mathrm{Mn}, \mathrm{Na}, \mathrm{P}$ and $\mathrm{Ti}$ were nebulized into the plasma, and the apparent concentrations of phosphorus, aluminium and iron were measured at the relevant analytical wavelength to check for any spectral emission originating from elements other than the analyte.

At these conditions it was found that $\mathrm{K}, \mathrm{Mg}, \mathrm{Mn}, \mathrm{Na}$ and Ti did not cause interferences at the lines chosen for $\mathrm{P}, \mathrm{Al}$ and $\mathrm{Fe}$. At the same conditions, however, spectral interferences were observed for $\mathrm{Ca}$ on $\mathrm{Al}, \mathrm{Al}$ on $\mathrm{P}, \mathrm{Fe}$ on $\mathrm{P}$ and $\mathrm{Cu}$ on $\mathrm{P}$.

The interference of $\mathrm{Ca}$ on $\mathrm{Al}$ could be compensated by background correction at low $\mathrm{Ca}$ concentrations. In practice, the Ca levels are low because of the poor solubility of calcium oxalate. To suppress any residual influence, background correction was applied on both sides of the $\mathrm{Al}$ line at distances of $0.10 \mathrm{~nm}$.

The spectral interference of $\mathrm{Al}$ on $\mathrm{P}$ is brought about by two phenomena: a broad-band continuum and an emission line at $215.05 \mathrm{~nm}$ (Fig. 1). In this situation background correction facilities at our instrument lead to overcompensation at higher Al levels. From Table 2 it follows that the overlap gives rise to an apparent $\mathbf{P}$ 


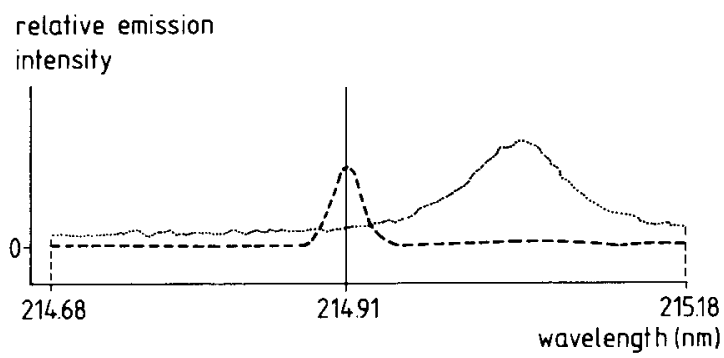

Fig. 1. Emission spectrum of $\mathrm{Al}$ and $\mathrm{P}$. Scan over $0.5 \mathrm{~nm}$ around $214.91 \mathrm{~nm}(\mathrm{P} \mathrm{I}), \ldots \mathrm{P} 10 \mathrm{mg}^{-1} ; \ldots . \mathrm{Al}$ $250 \mathrm{mg} \mathrm{I}^{-1}$.

concentration of $1 \mathrm{mg} \mathrm{l}^{-1}$ at an Al level of $155 \mathrm{mg} \mathrm{l}^{-1}$. This means that $10 \mathrm{mg} \mathrm{l}^{-1} \mathrm{Al}$ used as the highest standard gives an apparent $\mathrm{P}$ concentration of $0.07 \mathrm{mg} \mathrm{l}^{-1}$ (三 $0.43 \mathrm{mmol} P$ per $\mathrm{kg}$ soil). In soil extracts without any $\mathrm{Al}$ present this would mean that the measured $\mathrm{P}$ value is $0.43 \mathrm{mmol} \mathrm{kg}^{-1}$ too low. Actually, some $\mathrm{Al}$ is always present in soil extracts which tends to compensate for this error so that no special corrections are necessary. At $\mathrm{Al}$ concentrations falling beyond the standard series, however, on-line correction should be considered.

The interference of $\mathrm{Fe}$ on $\mathrm{P}$ is illustrated in Fig. 2. The overlap gives rise to an apparent $P$ concentration of $1 \mathrm{mg} \mathrm{l}^{-1}$ at a Fe level of about $930 \mathrm{mg} \mathrm{l}^{-1}$ (Table 2). Following the same reasoning as above, it can be inferred that an apparent $P$ concentration of about $0.01 \mathrm{mg} \mathrm{l}^{-1}(\approx 0.06 \mathrm{mmol} P$ per $\mathrm{kg}$ soil) would be caused by extractable $\mathrm{Fe}$ at a level of about $10 \mathrm{mg} \mathrm{l}^{-1}$. Hence, at Fe concentrations falling within the standard series negligible errors are made. As in the case of $\mathrm{Al}$, on-line correction is possible, but this would only be necessary at extremely high levels of extractable $\mathrm{Fe}$ in soils.

A very serious spectral interference in the determination of $P$ at $214.91 \mathrm{~nm}$ is caused by the copper emission line at $214.90 \mathrm{~nm}$. Aspiration of $\mathrm{Cu}$ at $1 \mathrm{mg} \mathrm{l}^{-1}$ gave a signal equal to $\mathrm{P}$ at $0.65 \mathrm{mg} \mathrm{l}^{-1}$. Furthermore, the peak search routine in the P-E instrument is designed in such a way that it cannot distinguish between two overlap-

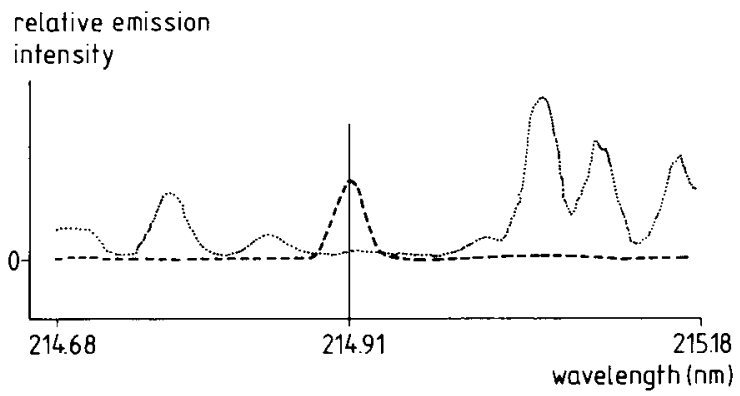

Fig. 2. Emission spectrum of Fe and P. Scan over $0.5 \mathrm{~nm}$ around $214.91 \mathrm{~nm}(\mathrm{P} \mathrm{I})$. --- P $10 \mathrm{mg} \mathrm{l}^{-1} ; \mathrm{Fe}$ $1000 \mathrm{mg} \mathrm{1}^{-1}$. 
Table 2. Spectral interference from $\mathrm{Fe}$ and $\mathrm{Al}$ at the $\mathrm{PI}$ emission line at $214.91 \mathrm{~nm}$.

\begin{tabular}{|c|c|c|}
\hline \multicolumn{2}{|c|}{ Solution composition } & \multirow{2}{*}{$\begin{array}{l}\mathrm{IEC}^{*} \\
\left(\mathrm{mg}^{-1}\right)\end{array}$} \\
\hline $\mathrm{Fe}\left(\mathrm{mg} \mathrm{l}^{-1}\right)$ & $\mathrm{Al}\left(\mathrm{mg} \mathrm{l}^{-1}\right)$ & \\
\hline 250 & 0 & 0.28 \\
\hline 500 & 0 & 0.54 \\
\hline 1000 & 0 & 1.03 \\
\hline 0 & 250 & 1.60 \\
\hline 0 & 500 & 3.23 \\
\hline 0 & 1000 & 6.44 \\
\hline 100 & 500 & 3.35 \\
\hline 250 & 250 & 1.84 \\
\hline 500 & 100 & 1.16 \\
\hline 500 & 500 & 3.67 \\
\hline
\end{tabular}

ping peaks, but looks for the top within a certain wavelength interval $( \pm 0.015 \mathrm{~nm})$ around the supposed position. This means, that the gross emission signal from solutions containing both $\mathrm{Cu}$ and $\mathrm{P}$ does not only depend on the actual concentrations of interferent and analyte, but also on the ratio of these concentrations. Fortunately, the solubility of copper (II) oxalate is low. At the extraction conditions used here (pH 3, oxalate $0.34 \mathrm{~mol} / \mathrm{l})$ the expected $\mathrm{Cu}$ concentration in the tenfold diluted extract is estimated to be at most $0.17 \mathrm{mg} \mathrm{l}^{-1}$. Moreover, the total copper content of soils is usually not high enough to reach even that value (Bowen, 1979). Indeed, ICP measurements of the present oxalate extracts at another $\mathrm{Cu}$ line $(324.75 \mathrm{~nm})$ resulted in zero values. It is obvious that $\mathrm{Cu}$ interferences may be present when extraction solutions with low $\mathrm{pH}$ and/or low oxalate concentrations are used. In such situations the use of a $\mathbf{P}$ line in vacuum UV may be considered.

It follows from the above discussion that all samples which gave emission values within the calibration range need not be corrected for spectral interference from $\mathrm{Al}$ or $\mathrm{Fe}$. In case of too high $\mathrm{Al}$ or $\mathrm{Fe}$ content, the extract should be diluted further; the value originally found for the $\mathrm{P}$ concentration should then be corrected for the influence of $\mathrm{Al}$ and/or $\mathrm{Fe}$.

\section{Analytical performance}

The results of analysis of soil extracts are given in Table 3 .

The results for the $\mathrm{P}$ determination show a good agreement between ICP-AES and the molybdenum blue method in the investigated range of $2-35 \mathrm{mmol} \mathrm{kg} \mathrm{k}^{-1}$ (Table 4).

For the Al determination also a good correlation was found between ICP-AES and FAAS. In the investigated range of $5-85 \mathrm{mmol} \mathrm{kg}^{-1}$ the difference was never 
Table 3. Analytical results for $\mathrm{Al}, \mathrm{Fe}$ and $\mathrm{P}$ measured by ICP-AES and reference methods in non-calcareous sandy soils ( $\mathrm{mmol} \mathrm{kg}^{-1}$ of air-dry soil).

\begin{tabular}{|c|c|c|c|c|c|c|}
\hline \multirow{2}{*}{$\begin{array}{l}\text { Soil } \\
\text { number }\end{array}$} & \multicolumn{2}{|l|}{$\mathrm{Al}$} & \multicolumn{2}{|l|}{$\mathrm{Fe}$} & \multicolumn{2}{|l|}{$\mathrm{P}$} \\
\hline & AAS & ICP & AAS & ICP & $\begin{array}{l}\text { spectrophoto- } \\
\text { metric }\end{array}$ & ICP \\
\hline 1 & 42.6 & 44.9 & 16.0 & 14.4 & 19.7 & 19.9 \\
\hline 2 & 51.6 & 52.7 & 16.6 & 14.7 & 20.7 & 20.7 \\
\hline 3 & 14.6 & 17.2 & 37.5 & 35.1 & 9.5 & 9.5 \\
\hline 4 & 71.8 & 70.4 & 12.4 & 11.4 & 10.2 & 10.1 \\
\hline 5 & 66.1 & 68.0 & 28.1 & 24.6 & 0.2 & $<2$ \\
\hline 6 & 56.0 & 57.4 & 5.1 & 4.1 & 1.4 & $<2$ \\
\hline 7 & 47.1 & 47.9 & 46.5 & 45.6 & 34.5 & 34.7 \\
\hline 8 & 49.3 & 48.5 & 49.1 & 44.8 & 34.9 & 35.4 \\
\hline 9 & 65.3 & 64.7 & 11.5 & 10.1 & 6.7 & 6.0 \\
\hline 10 & 33.8 & 32.3 & 7.3 & 6.2 & 9.6 & 7.9 \\
\hline 11 & 84.4 & 84.8 & 21.4 & 17.8 & 0.8 & $<2$ \\
\hline 12 & 69.2 & 69.7 & 6.1 & 5.3 & 0.6 & $<2$ \\
\hline 13 & 72.0 & 68.1 & 4.0 & 3.9 & 1.4 & $<2$ \\
\hline 14 & 55.9 & 57.3 & 28.7 & 27.5 & 0.4 & $<2$ \\
\hline 15 & 55.0 & 59.2 & 24.0 & 22.5 & 7.9 & 7.2 \\
\hline 16 & 22.8 & 26.2 & 8.3 & 7.1 & $<0.1$ & $<2$ \\
\hline 17 & 55.4 & 56.5 & - & 11.3 & 10.1 & 9.4 \\
\hline 18 & 50.9 & 52.7 & 44.8 & 44.5 & 6.6 & 5.5 \\
\hline 19 & 56.3 & 54.0 & 46.9 & 45.6 & 13.6 & 12.0 \\
\hline 20 & 7.2 & 5.5 & 22.8 & 21.3 & 1.2 & $<2$ \\
\hline
\end{tabular}

greater than $4 \mathrm{mmol} \mathrm{kg}^{-1}$, which is quite acceptable for the higher levels.

The values for Fe found by ICP-AES are consistently lower than those found by FAAS, on an average $2 \mathrm{mmol} \mathrm{kg}^{-1}$ in the investigated range of $4-45 \mathrm{mmol} \mathrm{kg}^{-1}$. It is not clear whether the ICP values are too low or the AAS values are too high. Apart from this systematic difference, however, the regression parameters show good correlation.

The sensitivity of the ICP compared with the reference methods used here is much higher in the case of $\mathrm{Fe}$ and $\mathrm{Al}$, while for $\mathrm{P}$ the sensitivity of ICP is limited. Winge et al. (1979) report for the $P$ line used a detection limit of $0.076 \mathrm{mg} \mathrm{l}^{-1}$.

In Fig. 3 is shown that the above described method for $P$ in routine analytical practice can be used down to $0.3 \mathrm{mg} \mathrm{l}^{-1}$ which corresponds with $2 \mathrm{mmol} \mathrm{P}$ per $\mathrm{kg}$

Table 4. Linear regression parameters for ICP determination of $\mathrm{P}, \mathrm{Al}$ and $\mathrm{Fe}$ with regard to the reference methods.

\begin{tabular}{lccc}
\hline Parameter & $\mathrm{P}$ & $\mathrm{Al}$ & $\mathrm{Fe}$ \\
Slope & 1.046 & 0.978 & 0.975 \\
Intercept & -1.18 & 1.7 & -1.0 \\
Correlation coefficient & 0.9986 & 0.9947 & 0.9976 \\
Number of observations & 12 & 20 & 19 \\
\hline
\end{tabular}




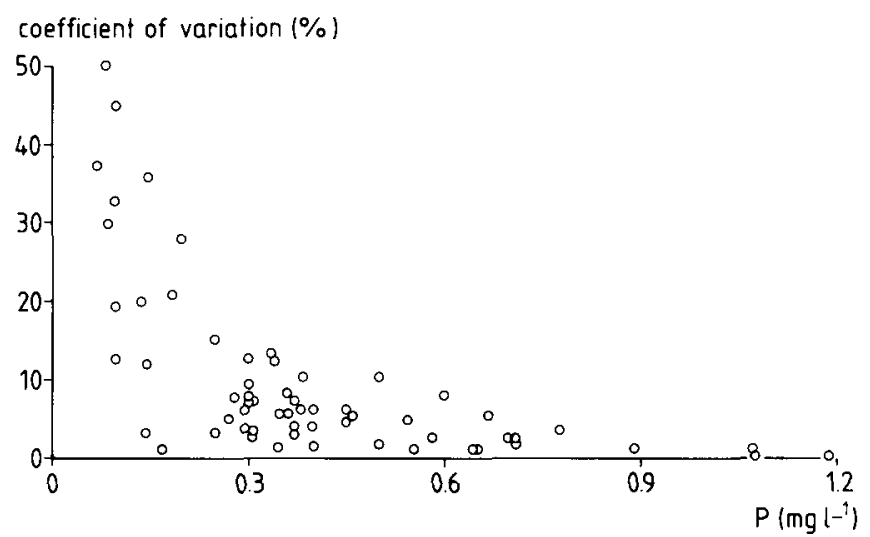

Fig. 3. Coefficient of variation of ICP-AES measurements as a function of $P$ concentration.

soil. At higher levels coefficients of variation of the measurements lie between 1 to $2 \%$.

The use of ICP-AES for these determinations offers the advantage of speed, since all three elements are measured almost simultaneously in one and the same extract, without further preparations except for a simple filtration and dilution. Because of the absence of serious interferences of the method, it is reasonable to assume that the usefulness is not limited to the sandy soils of the present study: the method may be applied to other soil types as well.

\section{References}

Beek, J., W. H. van Riemsdijk \& K. Koenders, 1980. Aluminium and iron fractions affecting phosphate bounding in a sandy soil treated with sewage water. In: A. Bamin \& U. Kalkafi (Eds.), Agrochemicals in soil, p. 369-378. Pergamon Press, Oxford/New York.

Blakemore, L. C., 1968. Determination of iron and aluminium in Tamm's soil extracts. New Zealand Journal of Agricultural Research 11: 515-520.

Bowen, H. G. M., 1979. Environmental chemistry of elements. Academic Press, p. 60.

Eck, R. van, 1978. Improvement of the nebuliser pattern of a flame photometer. Analyst 106: 409-410.

Murphy, J. \& J. P. Riley, 1962. A modified single solution method for the determination of phosphate in natural water. Analytica Chimica Acta 27: 31-36.

Saunders, W. M. H., 1965. Phosphate retention by New Zealand soils and its relationship to free sesquioxides, organic matter, and other soil properties. New Zealand Journal of Agricultural Research 8: $30-57$.

Schlichting, E., 1962. Über den Phosphathaushalt von Raseneisenboden. Phosphorsäure 22: 199-212.

Schwertmann, U., 1964. Differenzierung der Eisenoxide des Bodens durch Extraktion mit Ammoniumoxalat-Lösung. Zeitschrift für Pflanzenernährung, Düngung und Bodenkunde 105: 194-202.

Tamm, O., 1934. Über die Oxalat-methode in der chemischen Bodenanalyse. Meddn. Skogförsökanstalt 27: 1-20.

Winge, R. K., V. J. Peterson \& V. A. Fassel, 1979. Inductively coupled plasma-atomic emission spectroscopy. Prominent lines. Applied Spectroscopy 33: 206-219. 